Rabaska

Revue d'ethnologie de l'Amérique française

\title{
Récits du patrimoine
}

\section{René Bouchard}

Volume 18, 2020

URI : https://id.erudit.org/iderudit/1072920ar

DOI : https://doi.org/10.7202/1072920ar

Aller au sommaire du numéro

Éditeur(s)

Société québécoise d'ethnologie

ISSN

1703-7433 (imprimé)

1916-7350 (numérique)

Découvrir la revue

Citer ce document

Bouchard, R. (2020). Récits du patrimoine. Rabaska, 18, 281-284.

https://doi.org/10.7202/1072920ar

Ce document est protégé par la loi sur le droit d'auteur. L'utilisation des services d'Érudit (y compris la reproduction) est assujettie à sa politique d'utilisation que vous pouvez consulter en ligne.

https://apropos.erudit.org/fr/usagers/politique-dutilisation/
Cet article est diffusé et préservé par Érudit.

Érudit est un consortium interuniversitaire sans but lucratif composé de l'Université de Montréal, l'Université Laval et l'Université du Québec à Montréal. Il a pour mission la promotion et la valorisation de la recherche. https://www.erudit.org/fr/ 


\section{Récits du patrimoine}

RENÉ BOUCHARD

Société québécoise d'ethnologie

Au cours de l'année 2019, la Société québécoise d'ethnologie (SQE) a organisé une série de grandes conférences publiques qui se sont échelonnées sur deux cycles, à l'aune de cette maxime de vie de $\mathrm{M}^{\mathrm{gr}}$ Félix-Antoine Savard : "Le patrimoine oblige l'héritier». Visant un vaste auditoire, ces causeries scientifiques ont mis en vedette des experts reconnus du patrimoine et de la muséologie au Québec. Au cours de l'hiver et du printemps, un premier cycle de conférences, réalisé en partenariat avec l'Institut culturel du patrimoine de l'Université Laval, a porté sur l'analyse de vastes corpus de données ethnographiques souvent inédites et exceptionnelles dans le domaine de la photo aérienne, de la littérature orale, de l'art populaire et de l'artisanat. Avec l'ajout d'un troisième partenaire, le Monastère des Augustines, un second cycle s'est déroulé à l'automne, axé cette fois-ci sur la rencontre du patrimoine et de la muséologie.

Pierre Lahoud, historien et photographe, a inauguré cette série par une conférence donnée le 5 février 2019 sur « Le Québec vu du ciel : patrimoine, histoire et photographie aérienne ». Depuis 40 ans, le bureau de Pierre Lahoud prend les allures du cockpit d'un petit Cessna qui l'a fait voyager d'un bout à l'autre du Québec, poursuivant inlassablement sa quête du patrimoine québécois capté du haut des airs au moyen d'une caméra. Le résultat est spectaculaire. À travers les plis de la lumière rasante, les milliers de photographies de «l'historien volant », comme on l'a surnommé, montrent la vraie nature de l'habitat et du paysage façonnés par l'humain. Les photos ne mentent pas en effet et leur témoignage trop souvent implacable nous rappelle que la beauté est précaire et toute chose, mortelle. Promenant avec lui son auditoire vers des horizons insoupçonnés, vers l'ailleurs de l'architecture et des paysages, le conférencier tire du visible de ses photos une convergence vers l'invisible, vers une connaissance nouvelle de notre terre. Pierre Lahoud en a fait un mantra personnel : un devoir de mémoire s'impose à tous pour prendre la mesure de la fragilité de nos patrimoines, si essentiels à la diversité culturelle de l'humanité. 
Dans son exposé sur les «trajectoires du patrimoine oral des Français d'Amérique », Jean-Pierre Pichette, professeur retraité des universités de Sudbury en Ontario et Sainte-Anne en Nouvelle-Écosse, triple médaillé LucLacourcière, Marius-Barbeau et Germain-Lemieux pour son apport à l'étude de la littérature orale, a livré de son côté, le 26 février 2019, une démonstration rigoureuse et fascinante sur " la production spirituelle originale, complexe et vivante » de la littérature orale en terre d'Amérique. Citant le grand folkloriste français Paul Delarue pour illustrer la vitalité de cette tradition, le conférencier avance le chiffre des dix mille contes recensés ici à la fin des années 1970, soit autant de matériel fourni par les informateurs du cru que toutes les provinces de France réunies. Ce patrimoine vivant et distinctif - en fait foi ce nouveau cycle de chansons de voyageurs, de coureurs de bois et de forestiers qui lui est propre - a su s'adapter à son nouveau terroir jusqu'à influencer les populations amérindienne et anglophone. Comment comprendre que cette tradition ait pu se maintenir, se renouveler et s'enrichir avec autant de vigueur? Jean-Pierre Pichette est convaincu qu'un principe du limaçon permet de démonter les mécanismes de transformation opérant dans notre mémoire collective et d'expliquer la dynamique des traditions transmises davantage à la marge des collectivités excentrées que dans les grands centres.

Pour sa part, François Tremblay, directeur fondateur du Musée de Charlevoix et directeur des expositions et relations internationales du Musée de la civilisation du Québec au moment de sa retraite, a proposé à son auditoire, le 26 mars 2019, un survol étonnant de l'histoire de l'art populaire et une rencontre avec ses principaux acteurs. Se situant dans la continuité de son livre, Art populaire. Une histoire des débuts, sa conférence s'est attachée à préciser l'aventure euro-américaine des débuts de l'art populaire et à explorer l'origine d'un phénomène qui a balayé l'Europe et les Amériques, de la fin du XIX ${ }^{e}$ siècle jusqu'à la Seconde Guerre mondiale. De Paris à La Malbaie en Charlevoix, l'art populaire a fait irruption dans le champ des beaux-arts par le réseau des artistes modernes qui ont vu en lui des valeurs d'authenticité et d'art brut. Le douanier Rousseau s'est immiscé ainsi dans le Salon des Indépendants aux côtés de Matisse à l'aube du $\mathrm{Xx}^{\mathrm{e}}$ siècle. L'art populaire du Mexique, grâce à des artistes de la trempe de Frida Kahlo et de Diego Rivera, deviendra un instrument de promotion identitaire. De même, aux États-Unis, cet art oscillera entre modernité et identité, en se voyant associé à des qualités artistiques à travers le mouvement Arts and Crafts. Des personnalités de renom, Patrick Morgan en particulier, entraîneront dans ce sillage les peintres naïfs de Charlevoix, tels Robert Cauchon et les sœurs Bouchard qui feront la renommée de Charlevoix dans le domaine de l'art populaire au Québec.

Enfin, Jean-François Blanchette, chercheur associé au Musée canadien de l'histoire et spécialiste de la culture matérielle québécoise, a discouru, le 
30 avril 2019, sur 1'histoire des trois frères Bourgault et sur leurs mille apprentis. Rappelant la célèbre consigne lancée par Médard Bourgault (18971967) à ses élèves de Saint-Jean-Port-Joli, « Sculptez votre temps! », le conférencier a mis en évidence comment les trois frères Bourgault, Médard, André et Jean-Julien, appelés Les Trois Bérets, ont incarné une dynastie de sculpteurs sur bois dont la réputation a débordé les frontières du Québec. Les frères Bourgault sont devenus très vite, dans les années 1930 et suivantes, une icône du Québec catholique et rural très prisée par les Canadiens anglais et par les touristes étasuniens, ainsi qu'une figure identitaire du Canada français. Les frères Bourgault ont été à l'origine d'un mouvement sans précédent de sculpture sur bois en taille directe qui a fait vivre à une certaine époque près de 150 familles de Saint-Jean-Port-Joli et hissé ce village au rang de capitale canadienne de la sculpture sur bois.

Avec la collaboration de l'Institut du patrimoine culturel et du Monastère des Augustines, la $\mathrm{SQE}$ a poursuivi sa série des grandes conférences à l'automne 2019, sur le thème des Musées gardiens de la mémoire vivante, en conviant trois ténors de la muséologie québécoise à débattre du rôle des musées comme lieux de mémoire et acteurs de premier plan pour la sauvegarde et la mise en valeur du patrimoine.

Francine Lelièvre, directrice fondatrice du Musée Pointe-à-Callière, Cité d'archéologie et d'histoire, a exposé le 7 octobre 2019 comment la création de ce musée de ville in situ a renouvelé les approches de mise en valeur du patrimoine urbain. Ce complexe muséal retrace en effet plus de mille ans d'occupation humaine sur cette pointe qui a vu naître en 1642 le Fort Ville-Marie à l'origine de la fondation de Montréal. Résultat de dix ans de fouilles archéologiques, Pointe-à-Callière est classé site archéologique et historique du Canada, notamment grâce aux vestiges de sept structures et bâtiments anciens que le complexe muséal fédère aujourd'hui, ainsi qu'à sa collection archéologique et ethnohistorique de quelques 800000 artéfacts découverts sur les lieux, un attrait touristique exceptionnel. Dépositaire de sites historiques et identitaires incontournables - Fort Ville-Marie (1642), Place Royale (1676), ancien Hôpital général de Montréal (1693), château de Callière (1695), Parlement du Canada-Uni (1844) -, le Musée de Pointeà-Callière s'est métamorphosé en une cité muséale qui offre à ses visiteurs de marcher sur les traces des fondateurs de la ville, d'intégrer le temps à l'évolution de la cité de 1350 à nos jours et de situer les objets de sa riche collection dans un contexte in situ unique et original.

Quant à John Porter, directeur honoraire du Musée national des beaux-arts du Québec, il a convié, le 12 novembre 2019, le grand public à la redécouverte de son patrimoine à travers la genèse des collections initiales du Musée de la province, comme on l'appelait à cette époque, et la 
contribution fondatrice de personnalités oubliées ou méconnues, politiciens ou directeurs de l'institution, tels Athanase David, Charles-Joseph Simard, Pierre-Georges Roy, Paul Rainville et Gérard Morisset, des acteurs essentiels à son développement. À la faveur d'une relecture "décoiffante » des trente premières années du Musée national des beaux-arts du Québec, le conférencier, communicateur hors pair, a captivé son auditoire en raison de sa grande connaissance de l'institution qu'il a dirigée comme celle aussi de ses directeurs, en particulier Gérard Morisset et surtout Paul Rainville, un de ses prédécesseurs dans la fonction qui aura beaucoup contribué à ouvrir le musée des Plaines d'Abraham aux grands vents de l'art contemporain. Selon John Porter, en effet, l'institution muséale, « cette collectionneuse de collections ", ne se comprend bien que par l'histoire des directeurs qui les ont acquises et qui ont fait évoluer et rayonner cette institution jusqu'à devenir le Musée national des beaux-arts du Québec d'aujourd'hui.

Pour clore ce cycle des grandes conférences, Michel Côté, directeur honoraire du Musée des Confluences de Lyon et ex-directeur du Musée de la civilisation de Québec, a décortiqué, le 10 décembre 2019, le concept de musée de société de façon magistrale, en abordant les enjeux et tendances auxquels ce type de musée est confronté aujourd'hui ; changements sociaux, évolution des savoirs et enrichissement de la grammaire muséographique en bouleversent en effet les assises traditionnelles. Au-delà des enjeux économiques et budgétaires, les musées s'interrogent plus que jamais sur la pertinence de leur programmation (de quoi parlons-nous ?) et sur les types de savoirs offerts aux publics (à qui parlons-nous? et que veut-on transmettre ?). Comment répondre à ces changements, radicaux parfois, et quels sont les points de bascule qui en scandent le rythme ? Prenant appui sur l'exemple du Musée des Confluences, Michel Côté a illustré comment un tel projet culturel a pu se développer et offrir une programmation renouvelée, comment les collections ont pu se redéployer à partir d'une scénographie repensée, comment ont été vécus les enjeux architecturaux de son élaboration. Mais aussi, en faisant le pont entre la France et le Québec, comment le Musée de la civilisation a continué à sa manière de relire son concept fondateur et le développement de ses collections de façon originale et contemporaine. 